\title{
Effect of Prior Knowledge of Instructional Objectives on Students' Achievement in Selected Difficult Concepts in Nigerian Senior Secondary School Physics.
}

N. I. Nkwo, A. O. Akinbobola \& G. A. Ikitde

\section{Abstract}

The study examined the effect of prior knowledge of instructional objectives on students' achievement in selected difficult concepts in senior secondary school physics. A total of 100 senior secondary two (SS II) physics students were involved in the study. A non-randomized pretest-posttest control group design was used. From the findings, it was determined that students' prior knowledge of instructional objectives facilitates achievement on difficult concepts in physics. Generally, prior knowledge of behavioural objectives was found to be more effective in enhancing students' achievement on difficult concepts than prior knowledge of general objectives. Also, the results showed that male students achieved higher than female students given the same condition of exposure to prior knowledge of instructional objectives of physics difficult concept. Among others, it was recommended that physics teachers should introduce their lesson objectives in behavioural terms before the learning tasks begin at the instance of teaching the concept of electricity in senior secondary school physics.

Key Words: Prior Knowledge, Instructional Objectives, Behavioural Objectives, General Objectives, Students' Achievement, Difficult Concepts in Physics. 
Effects of Prior Knowledge of Instructional Objectives ...

\section{Introduction}

The achievement momentum of students in the classroom teaching and learning of physics varies according certain factors such as: student's background, learning environment, and developmental level in terms of chronological and cognitive maturity. Such variations lead to "labeling" students as under-achievers (limited learners), slow learners, dropouts, all being descriptions of weak and low ability group, and the "talented", generalized as high-ability group (Oxenhorne, 1992; Ali, 1998; Nkwo, 2003). These labels may arise from the overall misrepresentation of the nature of science learning in general, and physics learning in particular, as accentuated by "speeded" teaching in response to compulsion to complete the teaching syllabus (Wellington, 1982). As a consequence, an abysmal low achievement of students in physics class tests, internal and external (public) examinations seems to convey the idea that the entire participating students who enroll in these examinations for the last three decades, appear to be generally underachievers, slow learners and even dropouts. This trendy movement towards the direction of low achievement in physics learning could likely suggest that tomorrow's physics education practitioners may be bereft of techno-scientific competencies that dominate today's and future development, and service studies in technological application of physics, as applied in the goals of science (physics) education (Federal Republic of Nigeria FRN), 2002; FRN, 2004). In Oxenhorne's (1992) conception, underachievement is a low achievement due to inability of classroom instructional experiences to provoke the totality of the innate potentials of a learner; slow learning is a condition for which the learner's whole potentials have been provoked, reached, promoted and the learners is not motivated and interested to learn but still shows consistent low achievement. Dropouts mean learners who have 
opportunity of enrolling for schooling and studying in a given instructional programme but could not complete for one reason or another. It is acknowledged that the conditions of underachievement and dropouts are reversible, while that of slow learning is nearly irreversible. In either case, Okebukola (2002) notes that there are indications of limiting factors introducing distortions, obstacles, barriers, specific problems or impediments that partially or fully mitigate the holistic realization of the learner's potentials.

Ali (1998) identified such factors to include problems of malnutrition, poverty, unstable home background, pre-natal and post-natal disorders, unchallenging previous learning environment, teachers' and students' difficult in constructing understanding of concepts or language instructions. Of these factors, the most related one to this study is the last factor on difficulty in constructing understanding of concepts, arising from either one or a combination of these factors. Given the general description of unstable home background and previous learning environment of learner as a limiting factor, prior knowledge or entry behaviour or previous knowledge or base knowledge is identified (Uche, 1997). Edinyang (2006) defines it as knowledge available to the learner before a learning task begins, maintaining that it can interfere with later or present learning either retroactively or proactively. As any other, physics instruction is a cluster of decisions and activities culled into the teaching-learning situation (Duyilemi, 1982). Implied in FRN (1998), the senior secondary school curricula (sciences) contain four elements namely: topic, performance objectives, content and activities. Mostly concerned with this study is the "performance objectives provision" for which any effective teaching and meaningful 
Effects of Prior Knowledge of Instructional Objectives ...

learning (learning with associated understanding) must seek to realize.

The ever-increasing decline in physics enrolment and achievement, Ezeife (1996) points to the fact that there are increasing conditions for underachievement and slow learning in physics learning, portraying possible failures of previous efforts of science educators in improving the learning situation. Critically examined, all physics education practitioners and stakeholders contribute more or less to the deflections that characterize the physics-learning environment. Ali (1998), Ogunleye (1999), Ivowi (1999) and Okebukola (2002) present major problem areas of physics teaching and learning to include: students-related problems, problems of acquisition and or supply of instructional materials and laboratory equipment, irresponsible and lip-service attitudes of government and the general society towards physics education, problems arising from the technical and abstract nature of physics teaching-learning concepts, inadequate financing of science education, inadequate suitable qualified physics teachers, inadequate physic s textbooks, insufficient time in the school timetable due to other competing subjects and inferiority complex of girl-children in physics learning.

Also, the enveloping problems of underachievement and slow learning that attend physics learning are attributed by Ikwa (1997) to students' and teachers' ineffective grasp of concept due to difficulty in constructing understanding of these concepts. Uche (1997) and Ali (1998) add that the background of the student is a function of prior knowledge establishing the vital boundary constraints essential for identifying both sameness and uniqueness of novel information inputs.

Pearce and Roux (2006) are worried that the decline in physics achievement is below the conceptual threshold and is indicative of lack of problem solving competence. This 
broadens the conceptual gap arising from significant misconceptions hidden in difficulties encountered by students and teachers in understanding of concepts. Effiong (1999) carefully examined public examination records. He discovered that for West African Senior Secondary School Certificate Examination (WASSSCE), students' enrolment in physic never attained $20 \%$ of the total entry in any given year for the past three decades while chemistry and biology have at certain time exceeded $40 \%$ and $70 \%$ of the total entry respectively within the same period. This arises perhaps from both students' and teachers' inability to construct understanding of most physics concepts, called "difficult" concepts defined by Ivowi (1999) as concept difficult to teach and difficult to learn. Tackas (1996) noted that in general rating of school subjects by students and teachers, physics is acknowledged as a "hard and difficult" subject.

\section{Statement of the Problem}

From this general conception, it is therefore not unexpected that concept of a hard subject could be difficult to teach and learn. Given that any curriculum model is meaningful to the extent to which its objective are realizable and that alternative learning techniques and research effort in physics learning still face abject failures in finding potent solutions to problems of underachievement, slow learning, low enrolment and incidence of dropouts, all of which culminate in attendant poor performance in examination, the present study assumes overwhelming relevance and center-stage position in filling the conceptual gap. 
Effects of Prior Knowledge of Instructional Objectives ...

\section{Purpose of the Study}

The purpose of the study includes to:

i. determine the extent of achievement on difficult concepts among students having prior knowledge of general, behaviour objectives and those who do not have prior knowledge on instructional objectives.

ii. compare the extent of achievement on difficult concepts in physics between male and female students having prior knowledge of general, behavioural objectives and those who do not have.

iii. find out the extent of interaction of prior knowledge of instructional objectives and gender of students.

From the above, certain questions were formulated.

\section{Research Hypotheses}

In order to ensure focus, the following null hypotheses were formulated.

$\mathrm{HO}_{1}$ : There is no significant difference in achievement on difficult physics concept among students having prior knowledge of general, behavioural objectives and those who do not have prior knowledge of instructional objectives.

$\mathrm{HO}_{2}$ : The difference in achievement on difficult physics concepts between male and female students who have prior knowledge of general, behavioural objectives and those who do not have is not significant.

$\mathrm{HO}_{3}$ There is no significant interaction effect of prior knowledge of instructional objectives and gender on students' achievement on difficult concepts in physics.

\section{Research Method}

The research design adopted was the non-randomized pretest-posttest control group design. The population of the 
students was 620 SS II physics students in the twelve public secondary schools in Calabar Municipality. Three schools were randomly selected using simple random sampling technique through balloting. The sample size was 100 SS II physics students in the three selected schools in their intact class settings.

The researchers-made instrument named Physics Difficult Concepts Achievement Test (PDCAT), comprised 4 composite items on physics practical in the field subsection of the senior secondary school electricity physics. The instrument was adapted from Pearce \& Roux's (2006) Force Concept Inventory (FCI). The original questions were modified to suit a class of practical nature in order to measure students' construction of understanding of electricity concepts listed to be difficult. The WASSCE and NECO/SSCE past questions selected from the 2001-2006 examination items were used to formulate the instrument. The concepts tested included electric current $(\mathrm{I})$, electric resistance $(R)$, electric potential at a point $(\mathrm{V})$, electric potential difference between two points in the force field $(v)$, network (connections, arrangement and analyses) based on application of Ohm's laws. These question items were standardized, self-validating and reliable; being items already used on similar samples and was found to have produced possible results. More so, the items were presented to two physics teachers and two physics educators to ensure face and content validity. The instrument was trial-tested on a sample of forty SS II physics students in two schools of intact classes in Akamkpa urban of Akamkpa Local Government Area of Cross River State. The reliability coefficient of 0.82 was obtained using the Kuder-Richardson- 21 . 
Effects of Prior Knowledge of Instructional Objectives ...

\section{Research Procedure}

The treatment was facilitated by the problem-solving strategies, sequel to announcing the instructional objectives to the subjects in the experimental group and withholding it from the control or the "No-objective" group. In efforts to account for the pre-existing difference in the overall ability level between the groups, pretest was administered to both the experimental and control groups and the results were used as covariate measures.

Thereafter, the treatment began and lasted for three weeks. The teacher personality and quality variables were controlled as the research assistants (physics teachers in each school) were trained on how to present the instructional objectives during the lesson. The experimental group 1 (E1) was taught with general objectives while the experimental group 2 (E2) was taught with behavioural objectives. The control group (C) had no prior knowledge of the instructional objectives of the lesson and difficult "electricity" concepts using the designated lesson packages. The administration of the posttest was done after the treatment.

The data obtained were analyzed using Analysis of Covariance (ANCOVA) with pretest scores as covariates, Multiple Classification Analysis (MCA) was used to determine the contribution of the instructional objectives to the variation on students' academic performance and Scheffe pair wise comparison test was used as post hoc analysis to determine the direction of significance. All hypotheses were test at .05 level of significance.

\section{Results}

\section{Descriptive Analysis}

The descriptive analysis of the mean and standard deviation of pretest and posttest scores of experimental and 
control groups by levels of instructional objectives and gender is as shown in Table 1.

Table 1: $\quad$ Summary of mean and standard deviation of pretest and posttest scores of experimental and control groups by levels of instructional objectives and gender

\begin{tabular}{llllllll}
\hline Gender & $\begin{array}{c}\text { Instructional } \\
\text { Objective }\end{array}$ & $\mathrm{N}$ & \multicolumn{2}{c}{ Pretest Scores } & \multicolumn{2}{c}{ Posttest scores } & $\begin{array}{c}\text { Mean } \\
\text { Gain }\end{array}$ \\
& & & $\mathrm{X}_{1}$ & $\mathrm{SD}$ & $\mathrm{X}_{2}$ & $\mathrm{SD}$ & \\
\hline Male & $\mathrm{GO}$ & 19 & 14.32 & 2.52 & 80.74 & 10.69 & 66.42 \\
& $\mathrm{BO}$ & 20 & 14.00 & 2.15 & 78.50 & 12.58 & 64.42 \\
& NO & 19 & 12.53 & 1.74 & 33.58 & 2.87 & 21.50 \\
Total & Male & 59 & 13.62 & 2.26 & 64.52 & 23.81 & 50.90 \\
Female & GO & 14 & 14.29 & 2.70 & 47.29 & 8.62 & 33.00 \\
& BO & 13 & 14.00 & 2.00 & 79.23 & 13.13 & 65.23 \\
& NO & 15 & 12.27 & 1.67 & 33.33 & 3.83 & 21.23 \\
Total & Female & 42 & 13.48 & 2.30 & 52.19 & 21.17 & 38.71 \\
Total & GO & 33 & 14.31 & 2.61 & 64.02 & 9.66 & 49.71 \\
Total & BO & 33 & 14.00 & 2.08 & 78.87 & 12.86 & 64.87 \\
Total & NO & 34 & 12.40 & 1.71 & 33.46 & 3.35 & 21.06 \\
\hline
\end{tabular}

Where:

$\mathrm{GO}=$ General Objectives

$\mathrm{BO}=$ Behavioural Objectives

$\mathrm{NO}=$ No Prior Knowledge of the instructional objectives

As seen in Table 1, it is observed that the mean gain score of male students having prior knowledge of general objectives (66.42), is greater than the mean gain score of male students having prior knowledge of behavioural 
objectives (64.42), which in turn is greater than the mean gain score of male students that have no prior knowledge of the instructional objectives (21.50). The table also shows that the mean gain score of female students having prior knowledge of behavioural objectives (65.23) is greater than the mean gain score of female students having prior knowledge of general objectives (33.00) which in turn is greater than the mean gain score of female students that have no prior knowledge of instructional objectives (21.23). The table further shows that the mean gain score of students having prior knowledge of general objectives (66.42) is greater than the mean gain score of female students having prior knowledge of general objectives (33.00) while the mean gain score of female students having prior knowledge of behavioural objectives (65.23) is greater than the mean gain score of male students having prior knowledge of behavioural objectives (64.42). More so, the mean gain score of female students that have no prior knowledge of instructional objectives (21.23) is slightly less than the mean gain score of male students that have no prior knowledge of instructional objectives (21.50). Also, the mean gain score of male students (50.90) is greater than the mean gain score of female students (38.71).

The table also indicates that the mean gain score of students having prior knowledge of behavioural objectives (64.87) is greater than the mean gain score of students having prior knowledge of general objectives (49.71) which in turn is greater than the mean gain score of students that have no prior knowledge of instructional objectives (21.06).

\section{Hypothesis One}

There is no significant difference in the achievement of difficult physics concepts among students having prior knowledge of general, behavioural objectives and those who 
do not have instructional objectives. The analysis is as shown in Table 2.

Table 2: A $3 \times 2$ factorial analysis of covariance of instructional objectives using pretest scores as covariates.

\begin{tabular}{lllllcl}
\hline Sources of Variation & $\begin{array}{l}\text { Sum of } \\
\text { Squares }\end{array}$ & DF & $\begin{array}{c}\text { Mean } \\
\text { Square }\end{array}$ & F-cal. & $\begin{array}{c}\text { Sig. } \\
\text { of } F\end{array}$ & $\begin{array}{l}\text { Decision } \\
\text { at } P<.05\end{array}$ \\
\hline Pretest (Covariate) & 3236.05 & 1 & 3236.05 & 15.87 & 0.000 & $*$ \\
Main effects & 33791.03 & 2 & 16895.52 & 82.86 & 0.006 & $*$ \\
Explained & 34614.02 & 2 & 1737.01 & 84.88 & 0.000 & $*$ \\
Residual & 19778.42 & 97 & 203.89 & & & \\
Total & 5439.44 & 99 & 549.42 & & & \\
\hline
\end{tabular}

$*=$ Significant at $\mathrm{P}<.05 ;$ F-crit. $=3.92$

From Table 2 above, the instructional objectives main effect is significant at $P<.05$, since F-calculated of 82.86 is greater than f-critical of 3.92. Thus the null hypothesis is rejected. Consequent upon the existing significant deference in main effects, the Multiple Classification Analysis (MCA) is considered to determine the specific contribution of different levels of instructional objectives to the gain in students' achievement on difficult physics concepts.

Table 3: Multiple Classification Analysis MCA of posttest of students' having prior knowledge of instructional objectives and those without prior knowledge of instructional objectives in physics 
Effects of Prior Knowledge of Instructional Objectives ...

\begin{tabular}{|c|c|c|c|c|c|}
\hline Grand mean 59.34 & $\mathrm{~N}$ & Unadju & & $\begin{array}{l}\text { Adjusted for } \\
\text { Independent Variable } \\
\text { and } \\
\text { Covariates }\end{array}$ & \\
\hline Variable + Category & & Dev'n & Eta & Dev'n & Beta \\
\hline Go & & & 0.82 & & 0.84 \\
\hline Bo & 33 & 7.21 & & 7.52 & \\
\hline No & 33 & 19.45 & & 19.63 & \\
\hline $\begin{array}{l}\text { Multiple R. }=0.83 \\
\text { Multiple R. Squared }\left(R^{2}\right)=0.68\end{array}$ & 34 & -25.87 & & -26.36 & \\
\hline
\end{tabular}

Table 3 above indicates an index of relationship (0.84) of instructional objectives and students' achievement on difficult concept in physics. It further shows a multiple regression index $(R)$ of 0.83 and multiple regression squared index $\left(R^{2}\right)$ of 0.68 , showing that $68 \%$ the total variation of students' achievement on difficult concept in physics is attributed to prior knowledge of instructional objectives. In order to find the direction of significance, the posttest mean scores are subjected to Scheffe's pair wise comparison test for a post-hoc analysis.

Table 4: Results of Scheffe's post-hoc test multiple comparisons of instructional objectives on students' achievement on difficult concepts in physics

\begin{tabular}{|c|c|c|c|c|c|c|}
\hline $\begin{array}{l}\text { Instructional } \\
\text { Objectives }\end{array}$ & $\begin{array}{l}\text { Instructional } \\
\text { Objectives }\end{array}$ & $\begin{array}{l}\text { Mean } \\
\text { Difference (I-J) }\end{array}$ & $\begin{array}{l}\text { Std } \\
\text { Error }\end{array}$ & Sig. & $\begin{array}{l}95 \% \mathrm{Co} \\
\text { Interval } \\
\text { Lower } \\
\text { Bound }\end{array}$ & $\begin{array}{l}\text { Upper } \\
\text { Bound }\end{array}$ \\
\hline \multirow[t]{2}{*}{ Go } & BO & $-12.24 *$ & 3.30 & 0.002 & -20.45 & -404 \\
\hline & NO & $33.08 *$ & 3.28 & 0.000 & 24.93 & 41.22 \\
\hline \multirow[t]{2}{*}{ Bo } & GO & $12.24 *$ & 3.30 & 0.002 & 4.04 & 20.45 \\
\hline & NO & $45.32 *$ & 3.28 & 0.000 & 37.17 & 53.46 \\
\hline \multirow[t]{2}{*}{ No } & GO & $-33.08 *$ & 3.28 & 0.000 & -41.22 & 24.93 \\
\hline & BO & $45.32 *$ & 3.28 & 0.000 & -53.46 & 37.17 \\
\hline
\end{tabular}

The mean difference is significant at the .05 level.

$\mathrm{GO}=$ General objectives; $\mathrm{BO}=$ Behavioural objectives;

NO $=$ No objectives. 
From Table 4 above and based on the observed means, the mean difference between Bo and Go is 12.24; between Go and No are 33.08, and between $\mathrm{Bo}$ and No is 45.32. This implies that students' prior knowledge of behavioural objectives is the most effective in facilitating achievement on learning physics difficult concepts. This is followed by the students' prior knowledge of general objectives while no prior knowledge of instructional objectives is the least effective facilitating achievement on learning physics difficult concepts.

\section{Hypothesis Two}

The difference in achievement on difficult concepts in physics between male and female students who have prior knowledge of general, behavioural objectives and those who do not have is not significant.

The analysis is as shown in Table 5.

Table 5: $\quad 3 \times 2$ factorial analysis of variance of posttest scores of students' prior knowledge of instructional objectives and gender

\begin{tabular}{lllllll}
\hline Sources of Variation & $\begin{array}{l}\text { Sum of } \\
\text { Squares }\end{array}$ & DF & $\begin{array}{l}\text { Mean } \\
\text { Square }\end{array}$ & F-cal. & $\begin{array}{l}\text { Sig. } \\
\text { of F }\end{array}$ & $\begin{array}{l}\text { Decision } \\
\text { at } \\
\text { P<0.05 }\end{array}$ \\
\hline $\begin{array}{l}\text { Main Effects } \\
\begin{array}{l}\text { Instructional Objectives } \\
\text { Gender }\end{array}\end{array}$ & $\begin{array}{l}36165.43 \\
33233.57\end{array}$ & 2 & 12055.14 & 134.53 & 0.00 & $*$ \\
$\begin{array}{l}\text { 2-way Interaction } \\
\text { Objectives Vs Gender }\end{array}$ & 2931.86 & 1 & 2931.86 & 32.72 & 0.00 & $*$ \\
$\begin{array}{l}\text { Explained } \\
\text { Residual }\end{array}$ & 321.10 & 2 & 3050.05 & 3.45 & 0.08 & NS \\
Total & 42265.53 & 6 & 7044.25 & 78.61 & 0.00 & $*$ \\
\hline
\end{tabular}

$*=$ Significant at $\mathrm{P}<.05 ;$ F-crit. $=3.92 ; \mathrm{NS}=$ Not significant at $\mathrm{P}<.05$ 
Table 5 above shows that gender main effects is significant at $P<.05$. This indicates a rejection of the null hypothesis for the alternative hypothesis which proposes that there is a significant difference in achievement on difficult physics concepts between male and female students who have prior knowledge of general, behavioural objectives and those without prior knowledge of instructional objectives. Hence, the calculated f-value of 32.72 for gender main effect is greater than the critical f-value. In view of this existing difference, the MCA is computed to determine the specific level of gender factor that is responsible for the observed difference.

Table 6: Multiple Classification Analysis (MCA) posttest scores of students' prior knowledge of instructional objectives and gender

\begin{tabular}{|c|c|c|c|c|c|}
\hline Grand mean $=59.34$ & $\mathrm{~N}$ & Unadjusted & Eta & $\begin{array}{l}\text { Adjusted of } \\
\text { Independent } \\
\text { Variables + } \\
\text { Covariates } \\
\text { Dev'n }\end{array}$ & Beta \\
\hline Instructional Objectives & & & 0.82 & & 0.84 \\
\hline General Objectives & 33 & 7.21 & & 7.61 & \\
\hline Behaviour Objectives & 33 & 9.45 & & 19.37 & \\
\hline No Objectives & 34 & -25.87 & & -26.19 & \\
\hline Gender & & & -26 & & .23 \\
\hline Male & 58 & 5.18 & & 5.09 & \\
\hline Female & 42 & -7.15 & & -7.10 & \\
\hline \multicolumn{6}{|l|}{ Multiple R. $=.86$} \\
\hline Multiple R. Squared $=.74$ & & & & & \\
\hline
\end{tabular}

Table 6 indicates that the deviation of the adjusted posttest scores of male students from the grand mean of 59.34 is 5.09 while the deviation of the adjusted posttest scores of female students from the grand mean of 59.34 is 7.10. This implies that male students having prior knowledge of instructional objectives performed significantly better than their female counterparts. The multiple regression index $(R)$ is 
.86 and multiple regression squared index, $\left(R^{2}\right)$ is .74, represents $74 \%$ of the total variation in students' achievement on physics difficult concepts attributed to their prior knowledge of instructional objectives and gender.

\section{Hypothesis Three}

There is no significant interaction effect of instructional objectives and gender.

As shown in Table 5, the interaction effect is not significant at $P<.05$. The calculated $f$-value of 3.45 is less than the critical f-value of 3.92. Therefore, the null hypothesis stating a non-significant interaction effect of students' prior knowledge of instructional objectives and gender on achievement in difficult concepts in physics is retained. This implies that the effect of prior knowledge of instructional objectives on students' achievement in difficult concepts in physics is about the same at the two levels of gender.

\section{Discussion of Results}

The findings of the study showed that:

1. There is significant difference in achievement on physics difficult concepts among students who have prior knowledge of general objectives, behavioural objectives and those without prior knowledge of these instructional objectives.

2. There is significant difference in achievement on physics difficult concepts between male and female students who have prior knowledge of general, behavioural objectives and those who do not have prior knowledge of instructional objectives. 
Effects of Prior Knowledge of Instructional Objectives ...

3. There is no significant interaction effect of prior knowledge of instructional objectives and gender on students' achievement on difficult concepts in physics.

The first finding above is obtained from the results of analysis of hypothesis one in Table 2 and 3 in addition to the post-hoc analysis in Table 4, which indicate that prior knowledge of behavioural objective is most facilitating in enhancing students' achievement on difficult physics concepts. This is followed by the students' prior knowledge of general objectives while no knowledge of instructional objectives is the least effective in facilitating achievement on learning physics difficult concept. This is perhaps due to the unifying and anchoring ideas provided by the specification of these objectives conveying statements of particular actions demonstrable among the experimental groups, thereby leading to assimilation, accommodation and adaptation of concepts in the mental structures of the students. Hence, the superior academic gain is in support of the findings of Urevbu (1990), Inyang (1993), Ali (1998), Dogra (2003) in Edinyang (2006), Esu, Enukoha \& Umoren (2006) support this finding.

Also, the results of hypothesis two in Table 4 indicate a significant difference in achievement on difficult concepts in physics between male and female students who have prior knowledge of general, behavioural objectives. Impliedly, male students achieved higher than female students given the same condition of exposure to prior knowledge of instructional objectives of physics difficult concepts. Inomesia (1989) supports the researcher's finding that gender increases students' difficulties in understanding some primary school science concept in the direction of girl children. Recent studies by Okebukola (2002) and Pearce and Roux (2006) identify gender as a factor to be adapted while associating instructional material with conceptual representations in order to reduce misconceptions due to preconception notion and 
non-scientific beliefs of students rooted in their background. The affirmation of this finding may help to explain why more boys enroll in physics than girls: an observation common in nearly every physics classroom in Nigeria. Oyediji (1992) reports that gender is not an identifiable factor affecting pupils' difficulties in learning primary school mathematics concepts. This is a position of contrast to the finding of the study as its affects physics.

Similarly, the results of analysis of hypothesis three in Table 5 show a non-significant interaction effect of instructional objectives and gender on students' achievement on difficult physics concepts. This indicates that the effect of students' prior knowledge of instructional objectives on achievement in difficult concept in physics is about the same at the two levels of gender.

\section{Conclusion}

In conclusion, students' prior knowledge of behavioural and general objectives is more effective in facilitating achievement on difficult concepts in physics than without prior knowledge of these objectives. More so, students taught physics with properly articulated instructional objectives at behavioural level achieved and gain higher than those taught with general objectives and without objectives at all.

\section{Recommendation}

The study recommends that physics teachers should begin their lesson with introduction of, and emphasis upon behavioural objectives, while physics textbook authors should outline the objectives to be achieved in a given chapter or topic before content delivery. 
Effects of Prior Knowledge of Instructional Objectives ...

\section{References}

Ali, A. (1998). Strategies issues and trends in science education in Africa. Onitsha: Cape Publisher International Limited.

Dogra, D. D. (2003). Training teachers in mental health: Writing objective paper. A paper presented at the veterinary education department, University of Cambridge, Britain, $3^{\text {rd }}$ March.

Duyilemi, D. (1982). Relevance of some learning theories to primary school science teaching in Nigeria. Science Teachers Association of Nigeria (STAN) $23^{\text {rd }}$ annual conference proceedings. Lagos: Gilbert, Grace and Gabriel Associates, 80 - 86.

Ediyang, S. D. (2006). Prior knowledge of general objectives and specific behavioural objectives on students' achievement and retention in social studies in Akwa Ibom State of Nigeria. An unpublished Ph.D thesis, University of Calabar, Calabar.

Effiong, U. U. (1999). Physics teacher preparation for effective teaching of electricity and modern physics. In E. O. Ikwa, A. W. Egwaoje, \& U. U. Effiong, (Eds.), Proceedings of Science Teacher Association of Nigeria (STAN) National physics workshop/seminar.

Esu, A. E. O., Enukoha, O. I. \& Umoren, G. U. (2006). Curriculum development in Nigeria for colleges and universities. Calabar: Media Mark Associates.

Ezeife, A. N. (1996). Physics methods: The methodology of physics teaching. Enugu: University Trust Publishers.

Federal Republic of Nigeria (2002). National commission for colleges of education. Kaduna: NCCE.

Federal Republic of Nigeria (2004). National policy on education. Lagos: NERDC Press. 
Ikwa, E. O. (1997). Areas of difficulties in JSS integrated science curriculum as perceived by serving teachers in Cross River State. Akamkpa Journal of Science and Mathematics Education, 1 (1 \& 2), 126 - 134.

Inomiesa, E. (1989). Sex and school location as factors in primary school science achievement. Journal of Science Teachers Association of Nigeria, 26(1), 82 - 88.

Inyang, N. E. U. (1993). Psychological theories of learning: Relevance to science teaching. In I. T. Eshiet (Ed.), Methodology of science teaching: Historical and conceptual approach. Abak: Belpot (Nig). Co.

Ivowi, U. M. O. (1999). Strategies for effective teaching of electricity and modern physics. In E. O. Ikwa, A. W. Egwaoje, \& U. U. Effiong (Eds.), Proceedings of Science Teachers Association of Nigeria (STAN) National physics workshop/seminar, Calabar.

Nkwo, N. I. (2003). Effect of guided-inquiry and demonstration methods on secondary school students' acquisition of process skill in physics. An unpublished M.Sc. (Ed.) thesis, University of Uyo, Uyo.

Ogunleye, A. O. (1999). Science education in Nigeria: Historical development, curriculum reforms and research. Nigeria, Lagos: Sunshine International Publications (Nig) Ltd.

Okebukola, P. (2002). Beyond the stereotype to new trajectories in science teaching. Text of special lecture presented at the $43^{\text {rd }}$ Science Teachers Association of Nigeria (STAN) 19th 23rd August. 
Effects of Prior Knowledge of Instructional Objectives ...

Oyediji, O. A. (1992). Areas of difficulties in primary mathematics curriculum as perceived by in-service mathematics teachers. Journal of Science Teachers Association of Nigeria, $27(2)$, $66-70$.

Oxenhorne, J. M. (1992). Teaching science to underachievers in secondary school. New York: Globe Book Company.

Pearce, H. \& Roux P. (2006). The force concept inventory: It's meaning for teaching physics.

http://www.Aspectuct.Ac.Za/documents/fcimeaning,htm. http://modeling.La.Asu.,edu.

Tackas L. (1997). Teaching philosophy of Lacszlo Tackas.

http://physics, umbe.edu/m/tackas/teaching/htm/.

Uche, S. C. (1997). Assessment of students' learning in science. Akamkpa Journal of science and Mathematics Education (AJOSME), 1 (1), 31 - 44.

Urevbu, A. O. (1990). Curriculum studies. Ikeja: Longman Nigeria Ltd.

Wellington, J. J. (1982). What's supposed to happen, Sir? Some problems with discovery learning. Journal of Science Teachers Association of Nigeria (STAN), 2(1), 168 - 180. 